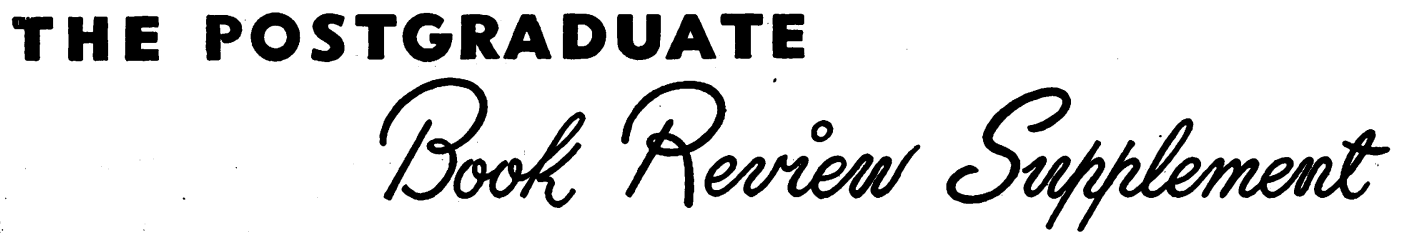

\section{A MANUAL OF PSYCHIATRY}

By K. R. Stallworthy, M.B., Ch.B. 2nd Edition. Pp. 314. Christchurch, New Zealand: N. M. Peryer, Ltd. 1953. 30s.

This is a brief (306 pages), workman-like and compact handbook of psychiatry which covers the whole field in a brisk and practical manner. There is no dead wood. The author writes as an experienced clinician and teacher and does not overweight his text with theory. The book will be useful for the senior student and general practitioner. The next edition will be more useful still to the practising doctor if the author could say a little more about psychotherapy and its scope and limits.

\section{D.O'N.}

\section{CLINICAL ENDOCRINOLOGY}

By Allan William Spence, M.A., M.D., F.R.C.P. Pp. xiii +696 , with 59 illustrations and 2 coloured plates. London: Cassell and Co., Ltd. 1953. 50 .

The author has written this book for ' the general physician and for those aspiring to become clinical endocrinologists.' He has succeeded in writing a book not only of inestimable value to these classes of practitioner but one which contains large sections of value to neurologists, gynaecologists and to surgeons who operate upon the ductless glands, as well as to many others.

The book, which has been excellently produced by the publishers on high quality paper and freely illustrated with photographic reproductions, cannot be said to be expensive. With the exception of diabetes mellitus it covers the whole field of primary endocrinological diseases as well as referring to more general disorders in which endocrinological factors play, or are thought to play, some part. Preceding each clinical section is a separate chapter dealing with the physiology of the hormones involved. These chapters are relatively short and largely concerned only with that physiology which is essential to a full understanding of the clinical disorders. A brief note of the modes of standardization of hormones is given in each case. Both physiological and clinical sections have historical introductions. Chapters on the clinical features of glandular disorders contain sections on aetiology and pathology, and in each case the problem of $\frac{\rho}{\circ}$ clinical diagnosis, differential diagnosis, laboratory diagnosis and treatment are fully discussed. Sufficient detail is given to enable the physician who is out of touch with this branch of medicine to treat cases without reference to any other literature.

There is a most useful appendix on steroid preparations and their methods of administration. The whole of the bibliography, which extends to 80 pages, is given at the end of the book, references being grouped under chapter headings and subheadings. This is followed by an index of authors. The arrangement of this, as of the whole book, is most convenient for the reader.

Most books of this size and quality are over long in Press and this possibly accounts for the omissiog of reference to a number of very recent develops. ments. The use of neomercazole in the treatment \& thyrotoxicosis is not mentioned, nor is the value of adrenocorticotrophic hormone in the treatment of hypopituitarism. In the management of unilateral adrenalectomy the author advises the use of deoxycortone acetate and omits reference to the value of cortisone. Total adrenalectomy for Cushing's syndrome in the absence of tumour is also not discussed.

The reviewer has produced these criticisms with difficulty because he conceives it his duty. They do not alter his view that this is an outstanding contribution to medical literature.

Dr. Spence has succeeded in bringing together a vast amount of material and it will be obvious to any reader that the book is the result of a very happy marriage between personal experience and a comprehensive knowledge of the literature of the subject.

$$
\text { N.D.C. }
$$

\section{PSYCHOTIC AND NEUROTIC ILLNESSES IN $\widetilde{\sim}$} TWINS

\section{M.R.C. Special Report Series No. 278}

By Eliot Slater, M.D., F.R.C.P., D.P.M. Pp. $\sigma$ vi + 385. London: H.M.S.O. 1953. 2 Is.

This is a study of mental illness in nearly 300 twins carried out by two skilled and critical ob- ? servers over a period of 13 years. There is much in $T$ it to fascinate anyone who tries to disentangle nature and nurture, and the case records in Part. II are 
lucid and concise. Evidence for the genetic factor in schizophrenia, affective disorders, psychopathy and neurosis, is clearly set out in the summary, and the reader can examine it and draw his own conclusions.

In their final paragraph the authors say 'A study of the personalities of the twins in all clinical groups shows that the basic make-up of the personality is largely determined by heredity.' This generalization may be true, but it is not warranted by the clinical material here presented. Proof of this proposition would require an examination of the life-patterns of twins with the same genetic make-up reared in contrasting environments from birth. In the series studied in this book only three pairs of twins were separated from each other in early life. .These three were binovular or non-identical twins. All that can be said, therefore, is that twins reared in the same family may show similarities, how much of this similarity is due to heredity and how much to environment is now, and I expect will remain, an open question.

D.O'N.

\section{AN APPROACH TO GENERAL PRACTICE}

By R. J. F. H. Pinsent, M.A., M.D. Pp. viii + 166. Edinburgh. E. \& S. Livingstone Ltd. 1953. I2s.

As the author points out, few students enter medicine with the avowed intention of becoming general practitioners. Most would prefer to spend their lifetime in the hospital atmosphere which has already become familiar to them, because they have had little opportunity of seeing the other side of the medal. This Dr. Pinsent succeeds in showing, with a comprehensive picture of general practice as it is today.

The early chapters contain many useful hints for the novice, ranging from medical ethics to equipping the G.P.'s bag and consulting room. Although a full chapter is given to a description of the formidable number of forms in current use in the N.H.S., the human side of medicine is not forgotten, and the recently qualified doctor who is contemplating entry into general practice will not only be encouraged but will find a wealth of valuable information in this book.

P.M.B.

\section{A DICTIONARY OF MIDWIFERY AND PUBLIC HEALTH}

By G. B. Carter, B.Sc.; S.R.N., S.C.M., M.T.D., and G. H. DoDDs, M.D., F.R.C.S., F.R.C.O.G. Pp. 686, illustrated. London: Faber \& Faber Ltd. 1953. 25s.

The authors must be congratulated on producing this book which is full of useful, concise facts and sound, up-to-date practical advice. This is much more than a dictionary, the section of breast feeding, for example, being over seven pages long with four illustrations. The vast majority of these discussions are first class, the ones on uterine inertia, anuria and pre-eclampsia being especially commendable.
About roo pages are devoted to public health and administration, and the field covered ranges; from ' UNESCO' ' at one extreme to 'iscabies' at the other.

Only very occasionally does the book lapse into its most likely pitfall, that of long hypothetical lists - thus eighteen causes of abortion are enumerated, of which six are dubious in the extreme.

However, this is a book which not only might well be in every labour ward sister's office, but could also be studied to advantage by the medical practitioner.

\section{D.W.S.G.}

\section{APPLIED CYTOLOGY}

By G. R. Osborn, M.B., B.S. Pp. xi +168 , with 131 illustrations. London: Butterworth and Co., Ltd. I953. 35s.

This books gives an account of the technique and criteria adopted for the cytological diagnosis of cancer of the uterus, bronchus, breast and bladder. The main part of the work is devoted to the first of these, in which the author appears to have considerable experience. Much valuable information is given including the shortcomings of the methods.

The chief criticism of the work is that a much more detailed correlation between cytological diagnosis, histology of the biopsy and examination of the gross specimen when available could have been made. Such correlation is essential in assessing the accuracy of purely cytological'methods of diagnosis.

The book is profusely illustrated with excellent photographs.

R.H.H.

\section{THERAPEUTICS IN INTERNAL MEDICINE}

Edited by F. A. KYSER, M.D., F.A.C.P. 2nd

Edition. Pp. xxi +830 . London: Cassell \&

Co., Ltd. I953. I Ios.

This book is a reliable guide to therapeutics and can be recommended. It consists of a series of articles on the treatment of practically every known disease. These have been written by some 84 American physicians. The only real criticism that can be levelled at the book is one that can be levelled against any textbook of therapeutics, namely that treatment cannot be discussed without extensive reference to the nature of the condition being treated. Any textbook of therapeutics must therefore, of necessity, also be a textbook of medicine. The authors of this book have clearly realized this and they have frequently included brief sketches of the diseases the treatment of which they describe, but the result can never be as satisfactory as a textbook dealing in detail with both medicine and therapeutics. However, for those who prefer a single volume of therapeutics this is more successful than most. The standard of the individual articles is uniformly high. Two perhaps call for special mention: a delightful article on the treatment of psychosomatic problems by Dr. Walter Alvarez, 